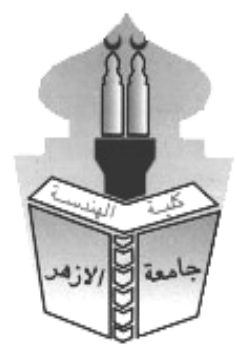

\title{
EFFECT OF STRAIN RATE OF LOADING ON TENSILE STRENGTH AND STIFFNESS OF POLYESTER GEOGRIDS
}

\author{
Abdelwahab Tahsin ${ }^{* 1}$, Rami El-Sherbiny ${ }^{2}$ and Abdelsalam Salem ${ }^{2}$ \\ ${ }^{1}$ Arab Consulting Engineers Office, Dokki, ,Cairo, Egypt \\ ${ }^{2}$ Geotechnical and Foundations Engineering, Department of Public Works, Faculty of \\ Engineering, Cairo University, Egypt. \\ *Corresponding author Email: wahab.3000@yahoo.com
}

\begin{abstract}
Geosynthetics are being widely used as a cost-effective soil reinforcement solution. The use of geogrids to improve soil mechanical behavior has become increasingly common practice in geotechnical engineering applications, as it has unique advantages over other soil improvement techniques due to technical, economical, constructability and sustainability aspects. Mechanical properties of geogrids are of great importance in designing with geogrids. This papers discusses the effect of strain rate of loading on the tensile strength pf polyester (PET) geogrids. This paper presents the results and analysis of laboratory constant strain rate (CSR) tests conducted on polyester (PET) geogrids at strain rates varying from $0.10 \%$ to $20 \%$ strain per minute. Assessment of variation of geogrid stiffness with time (creep effect) and calibration factor between global to local strains were derived. A proper material characterization of geogrid is essential for numerical finite element modeling. The modeled behavior of reinforced structures is sensitive to the geogrid stiffness rather than the geogrid strength. The higher CSR results in increase of the measured strength and secant modulus. The larger ultimate strength, the higher anticipated secant modulus. The calibration factor CF between global to local strains ranged from 2.08 to 1.99 was measured for the tested polyester geogrid specimens at a stain of $2 \%$. This CF estimation for strain of $2 \%$ is in agreement with comparable PET geogrid CF of 2.2, which was introduced by Allen et al. (2002).
\end{abstract}

KEYWORDS: Geogrid Wall, Geo-Synthetic Reinforced Soil (GRS), Strain; Strain Gauge, Creep; Constant Strain Rate CSR Test, Calibration Factor, Secant Modulus; Geogrid Stiffness, Tensile Strength, Rate Of Loading.

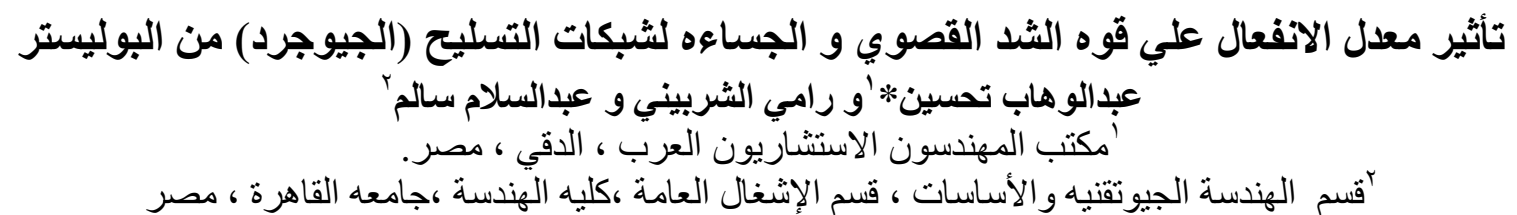

* البريد الاليكترونى للباحث الرئيسى : Email :wahab.3000@yahoo.com:

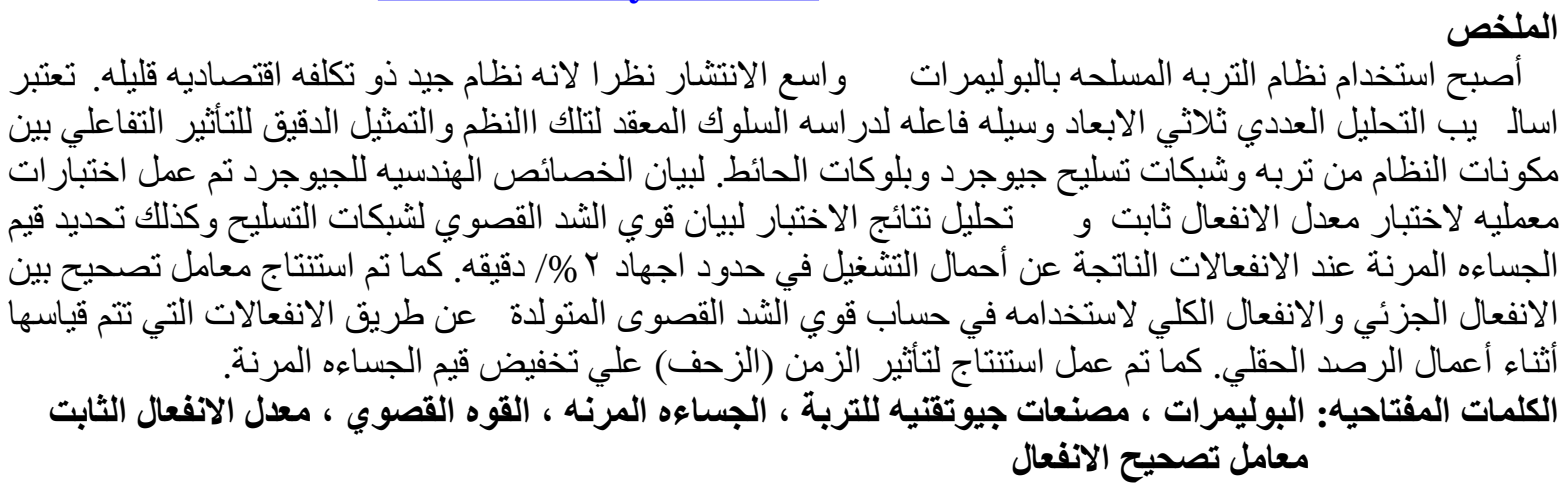




\section{INTRODUCTION}

Geosynthetics are being widely used as a cost-effective soil reinforcement solution. Conceptually, the behavior of reinforced soil structure is complicated due to the mechanical complexity of component materials, their interactions, geogrid properties, soil type and wall geometry. Current design methods in North America for internal stability are based on limitequilibrium tie-back wedge methods of analysis that were adapted from steel reinforced soil retaining wall design (AASHTO 2002). Numerical modeling of geo-synthetic reinforced soil systems is now widely used for the design of field structures, prediction of measured responses, and in research to generate synthetic data for the purpose of filling in knowledge gaps on the behavior of these systems. (Yan Yu and Richard J. Bathurst, 2016). In this research work, we are focused on conducting proper geogrid characterization necessary for numerical simulations that can be used to predict operational (working stress) conditions rather than incipient wall collapse. A proper material characterization of geogrid is essential for numerical finite element modeling. The current study comprises 5 nominated types of geogrid (A, B, C, D and E) with varying strength and stiffness. The standard raw material of these geogrids is the high-modulus polyester (PET), which of high stiffness, low creep and uniform product strength.

\section{TEST APPARATUS AND SPECIMEN PREPARATION}

TESTOMETRIC M500- 50CT Universal Testing machine was used to perform the geogrid load-extension under Constant Strain Rate CSR. The apparatus comprises main tensile machine, pressure jack and computer control unit. The tensile machine consists mainly of clamps, sensors for recording the tensile force, and other sensors to monitor the extent of grips separation. The clamps must be attached with suitable pressure to avoid slippage. Clamping pressure must be equal for all specimens under the same test to manage consistent judgment between the anticipated results. Fig. 1 presents photos of the tensile test apparatus and specimen installation prior to start of strain loadings. According to the Multi-Rib tensile method of ASTM D6637 "Standard Test Method for Determining Tensile Properties of Geogrids by the Single or Multi-Rib Tensile Method"; the specimen is schematically illustrated at Fig. 2 should be a minimum of $200 \mathrm{~mm}$ wide and contains five ribs in the cross-test direction by at least three junctions or $300 \mathrm{~mm}$ long in the direction of the testing. The outermost ribs are cut prior to testing to prevent slippage from occurring within the clamps. Thus, the width of intact ribs is $120 \mathrm{~mm}$. The room ambient temperature was $20^{\circ} \mathrm{c}$ during test procedures.

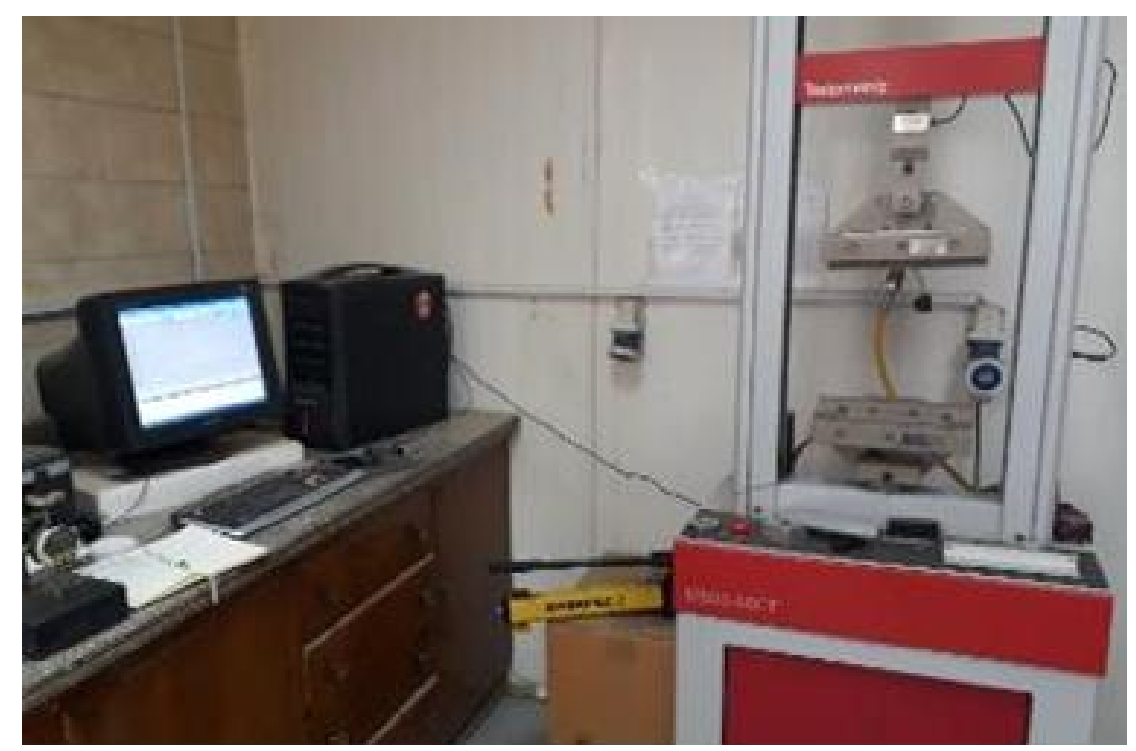

Fig. 1 Constant Strain Rate CSR Tensile test apparatus 

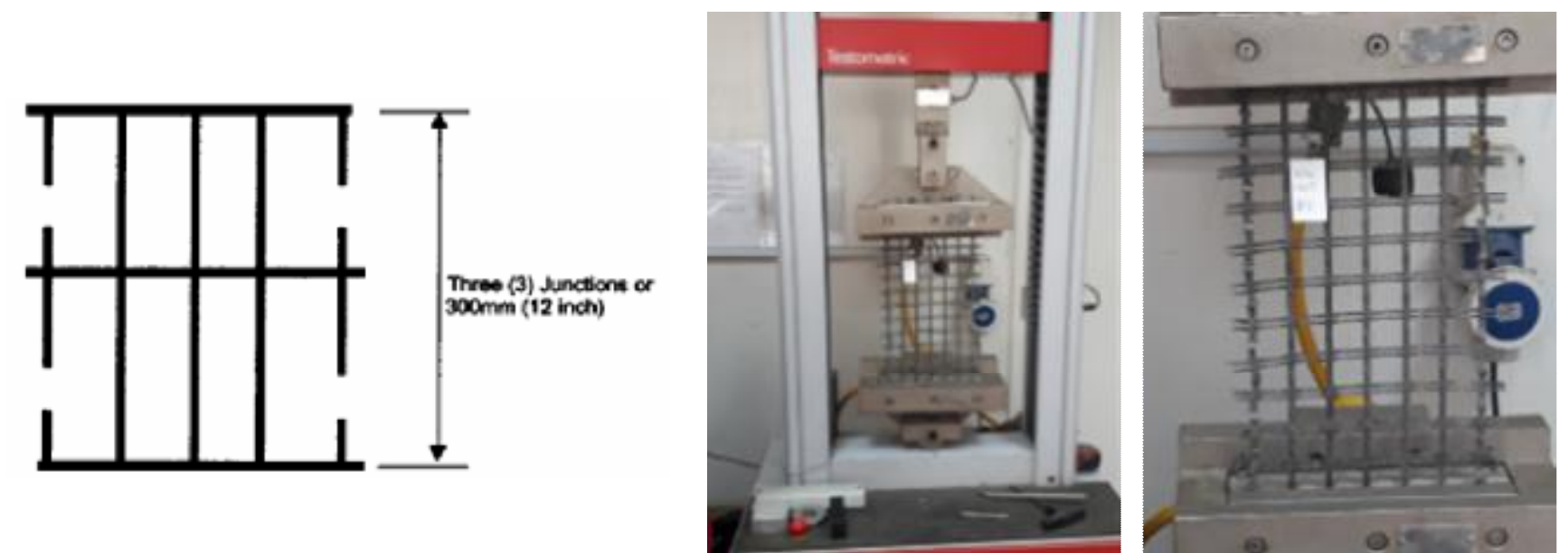

Fig. 2 Specimen configuration; Multi-Rib tensile method -ASTM D6637

\section{TENSILE LOAD VERSUS STRAIN TEST RESULTS}

The current study comprises 5 nominated types of geogrid (A, B, C, D and E) with varying strength and stiffness. Table 1 listed the physical properties of geogrid types. The standard raw material of these geogrids is the high-modulus polyester (PET), which of high stiffness, low creep and uniform product strength. The geogrid specimens were tested on a tensile test machine under Constant Strain Rate (CSR) test in accordance with ASTM D6637, to investigate: (a) Tensile ultimate strength $\mathrm{KN} / \mathrm{m}$, and (b) strain at break. The secant modulus (J) KN/m at strain of $1 \%$ and $2 \%$ were derived based on the tensile force- strain relationship which is necessary for numerical modeling simulation. The CSR was varied to study the effect of strain rate of loading on the tensile strength and stiffness of the PET geogrid. In addition to develop an assessment for variation of stiffness with time and derive a calibration factor between global to local strain.

Table 1: Physical properties for the tested geogrid types as per manufacture data sheets.

\begin{tabular}{|c|c|c|c|c|c|c|}
\hline PROPERTY & TEST & $\mathbf{A}$ & B & C & D & $\mathbf{E}$ \\
\hline Mass/Unit Area $\left(\mathrm{g} / \mathrm{m}^{2}\right)$ & ASTM D-5261 & 185 & 240 & 320 & 350 & 440 \\
\hline Aperture Size (mm) & measured & $25 \times 25$ & $25 \times 25$ & $25 \times 25$ & $25 \times 25$ & $25 \times 25$ \\
\hline Percent open area & CWO 22125 & $\mathbf{7 0 \%}$ & $\mathbf{7 0 \%}$ & $65 \%$ & $65 \%$ & $62 \%$ \\
\hline $\begin{array}{l}\text { Ultimate wide width } \\
\text { (MD) Tensile Strength } \\
\text { (KN/m) }\end{array}$ & ASTM D-6637 & 35 & 55 & 80 & 110 & 150 \\
\hline $\begin{array}{l}\text { Elongation at ultimate } \\
\text { tensile strength -MD }\end{array}$ & ASTM D-6637 & $\leq 10 \%$ & $\leq 10 \%$ & $\leq \mathbf{1 0 \%}$ & $\leq 10 \%$ & $\leq 10 \%$ \\
\hline $\begin{array}{c}\text { Long term design } \\
\text { strength- } \mathrm{MD}(\mathrm{KN} / \mathrm{m})^{*}\end{array}$ & GRI GG4 & 18.8 & 29.5 & 42.9 & 59 & 81 \\
\hline Standard Roll Size (m) & & $5 \times 100$ & $5 \times 100$ & $5 \times 100$ & $5 \times 100$ & $5 \times 100$ \\
\hline Weight (Kg) & & 114 & 141 & 182 & 192 & 205 \\
\hline
\end{tabular}

* To be reduced by factors: Durability $=1.2$ and Installation $=1.2$.

Minimum of three to five single tests were performed on the machine direction (MD) for each product type A, B, C, D \& E, in accordance with ASTM D6637 using the multi- rib tensile method. A range of CSR was applied to study its effect on tensile strength and stiffness, which includes $20 \%, 10 \%, 6 \%, 3 \%, 1 \%$ and $0.05 \%$ strain $/ \mathrm{min}$. The tensile strength was defined at peak load, while the secant modulus (J) was defined at strain level $1 \%$ and $2 \%$. Since the geogrid CSR tests were carried out at the same in-door ambient temperature of $20^{\circ} \mathrm{C}$, temperature effect was not a factor in the test results accuracy. Sample of the test results for five specimens at $20 \% / \mathrm{min}$ is presented at Fig. 3. 


\subsection{INFLUENCE OF STRAIN LOADING RATE ON STRENGTH}

Determination of the ultimate strength is based on the peak strength measured during CSR of $10 \%$ strain/min- ASTM D 4595; after Hatami and Bathurst 2005. Based on the test results, range of 1.92-1.75 was derived for FOS which is safely covered the deemed long term strength as well as durability and installation factors (reductions) with wide acceptable margin as shown at Table 2. The linear approximation of tensile load- strain response is considerable accepted in the strain domain up to $2 \%$ which covers a wide scatter of Geosynthetics reinforced structures conditions under service loadings.

The influence of CSR of the strength is illustrated at Fig. 4 for the different geogrid specimens where, the recorded tensile load increased as the CSR increased.
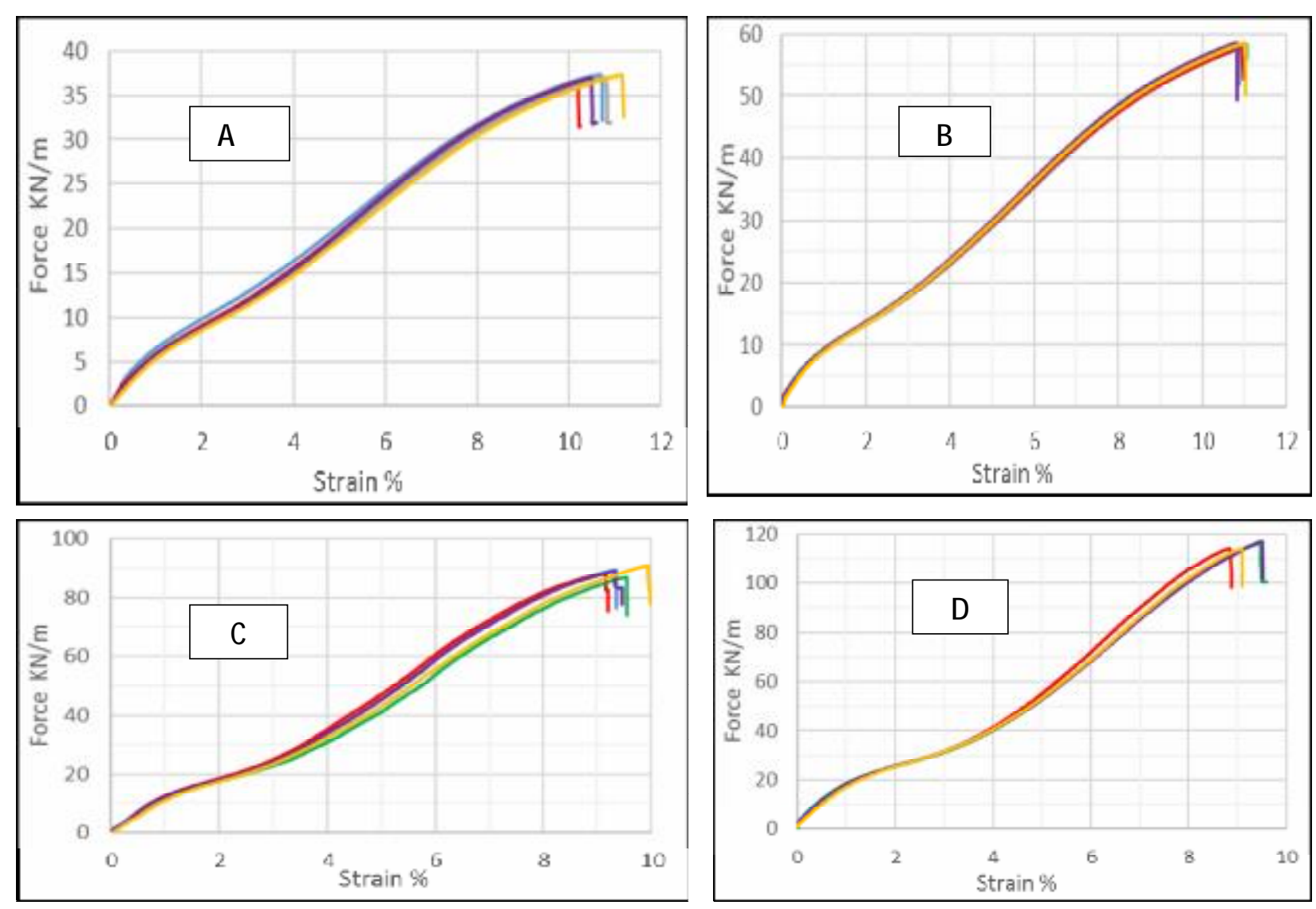

Fig. 3 Force- strain response @ CSR $20 \% / \mathrm{min}$ for five tested specimens of types A, B, C\& D 
EFFECT OF STRAIN RATE OF LOADING ON TENSILE STRENGTH AND STIFFNESS OF POLYESTER GEOGRIDS

Table 2: CSR test results for 10\% strain/min- ASTM D 4595.

\begin{tabular}{|c|c|c|c|c|c|c|c|c|c|c|c|}
\hline Type & Test & $\begin{array}{l}\text { Peak } \\
\text { Force } \\
\text { (KN) }\end{array}$ & $\begin{array}{c}\text { Tensile } \\
\text { strength } \\
(\mathrm{KN} / \mathrm{m})\end{array}$ & $\begin{array}{c}\text { Secant } \\
\text { modulus } \\
\text { KN/m } \\
\text { (strain } \\
2 \% \text { ) }\end{array}$ & $\begin{array}{c}\text { Strain } \\
\text { at } \\
\text { peak } \\
\%\end{array}$ & Type & Test & $\begin{array}{c}\text { Peak } \\
\text { Force } \\
(\mathbf{K N})\end{array}$ & $\begin{array}{c}\text { Tensile } \\
\text { strength } \\
(\mathrm{KN} / \mathrm{m})\end{array}$ & $\begin{array}{c}\text { Secant } \\
\text { modulus } \\
\text { KN/m } \\
\text { (strain } \\
2 \% \text { ) }\end{array}$ & $\begin{array}{c}\text { Strain } \\
\text { at } \\
\text { peak } \\
\%\end{array}$ \\
\hline \multirow{6}{*}{ A } & 1 & 4.30 & 35.85 & 384 & 10.3 & \multirow{6}{*}{ C } & 1 & 11.06 & 92.19 & 859 & 11.1 \\
\hline & 2 & 4.41 & 36.74 & 377 & \multirow{2}{*}{$\frac{10.6}{9.5}$} & & 2 & 9.69 & 80.75 & 822 & 10.0 \\
\hline & 3 & 3.87 & 32.27 & 395 & & & 3 & 10.95 & 91.24 & 854 & 11.0 \\
\hline & 4 & 4.21 & 35.07 & 389 & 10.3 & & 4 & 8.81 & 73.42 & 923 & 9.9 \\
\hline & 5 & 3.77 & 31.44 & 403 & 9.0 & & 5 & 8.09 & 67.42 & 883 & 8.3 \\
\hline & mean & 4.11 & 34.27 & 390 & \multirow{2}{*}{$\begin{array}{c}9.9 \\
11.5\end{array}$} & & mean & 9.72 & 81.00 & 868 & 10.1 \\
\hline \multirow{6}{*}{ B } & 1 & 7.23 & 60.28 & 546 & & \multirow{6}{*}{ D } & 1 & 15.7 & 130.83 & 1099 & 11.9 \\
\hline & 2 & 7.08 & 58.98 & 528 & 11.4 & & 2 & 15.08 & 125.67 & 1126 & 11.2 \\
\hline & 3 & 6.12 & 51.03 & 512 & 10.7 & & 3 & 14.06 & $\mathbf{1 1 7 . 1 3}$ & 1095 & 10.8 \\
\hline & 4 & 6.05 & 50.43 & 537 & 9.6 & & 4 & 11.48 & 95.67 & 1165 & 9.1 \\
\hline & 5 & 6.10 & 50.83 & 558 & 10.8 & & 5 & 11.32 & 94.33 & 1153 & 8.9 \\
\hline & $\begin{array}{l}\text { mean } \\
\text { Bvgf }\end{array}$ & 6.52 & 54.31 & 536 & 10.8 & & mean & 13.53 & 112.73 & 1128 & 10.4 \\
\hline & 160 & & & & & & 160 & & & & \\
\hline & 140 & & & $-10 \%$ stt & $\mathrm{in} / \mathrm{min}$ & & 14 & & & $-10 \% \mathrm{~s}$ & $\mathrm{rain} / \min$ \\
\hline$\Xi$ & & A & & $-6 \%$ stra & nimin & & 140 & B & & $-6 \% \mathrm{~s}$ & in/min \\
\hline $\bar{z}$ & 120 & & & $\begin{array}{l}-3 \% \text { stra } \\
-1 \% \text { stra }\end{array}$ & $1 / \min$ & $\xi$ & 120 & & & $\begin{array}{l}Z^{3} 9 \% \text { st } \\
-1 \% \text { st }\end{array}$ & in 1 in $/ \min$ \\
\hline 8 & 100 & & & & & 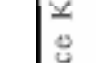 & 100 & & & $\begin{array}{c}3+x \\
\end{array}$ & 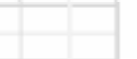 \\
\hline$\underline{\underline{g}}$ & 80 & & & & & 号 & 80 & & & 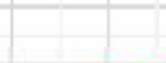 & \\
\hline$\frac{0}{\bar{n}}$ & 60 & & & & & $\frac{0}{72}$ & 60 & & & $=$ & \\
\hline 巴ల & 40 & & & & & 5 & 40 & & & & \\
\hline & 20 & & & & & & 0 & & & & 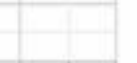 \\
\hline & 0 & 2 & $\begin{array}{c}6 \\
\text { Strain } \%\end{array}$ & 10 & 14 & & 0 & 2 & $4 \underset{6}{6}$ Strain \% & 10 & 12 \\
\hline
\end{tabular}
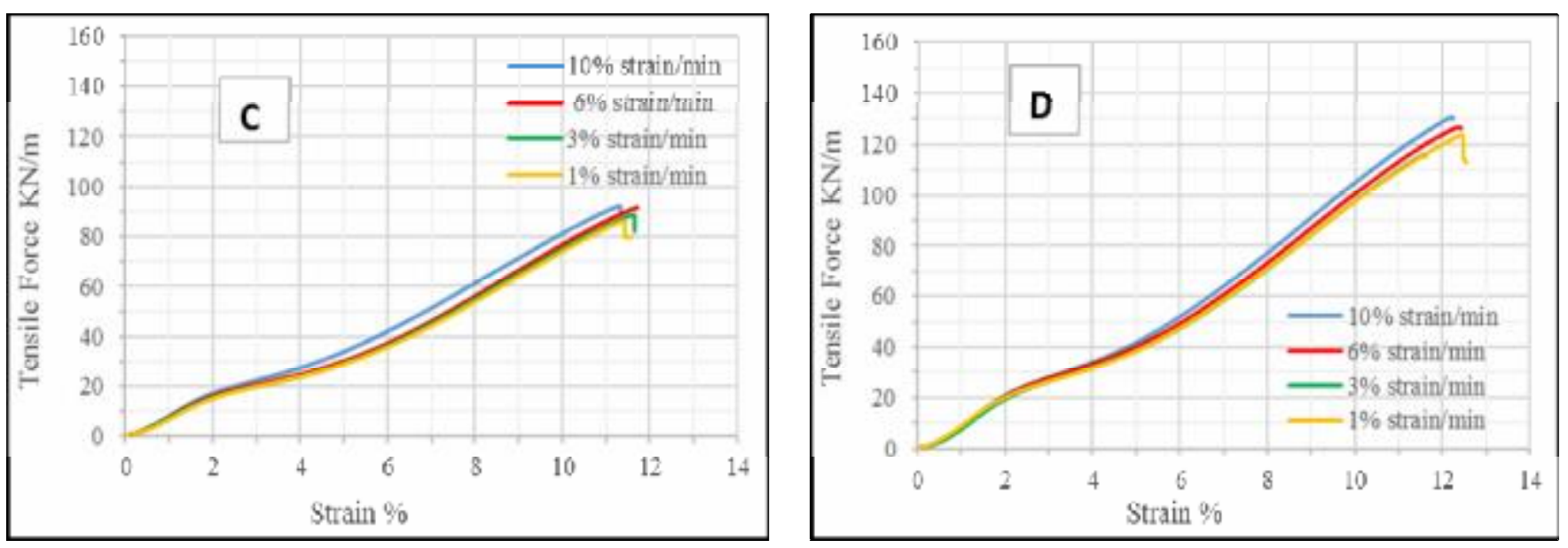


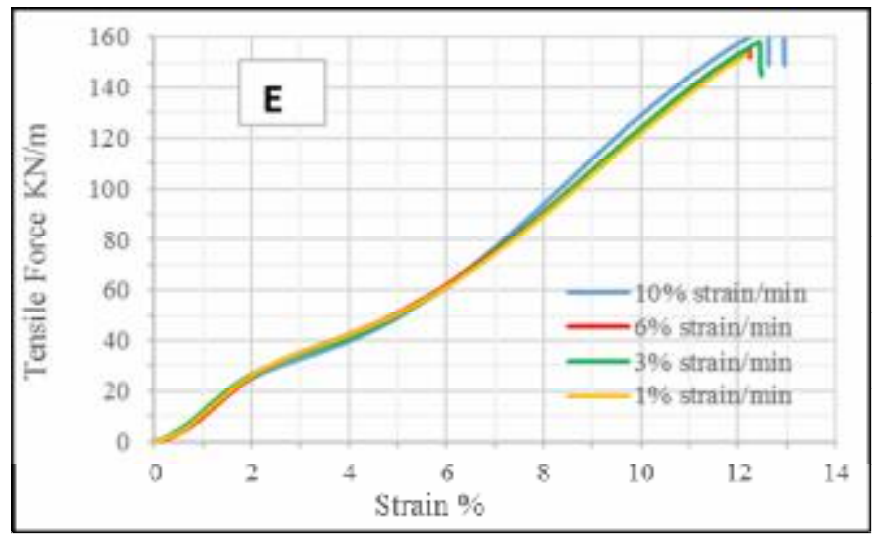

Fig. 4 Influence of strain rate of $10,6,3 \& 1 \% / \mathrm{min}$ at types $A, B, C, D \& E$

\subsection{SECANT MODULUS}

The sample total width is $200 \mathrm{~mm}$, while the intact width is limited to $120 \mathrm{~mm}$. According to ASTM D6637, clause 8.2.4 stated that "Within test methods A, B and C the outermost ribs are cut prior to testing to prevent slippage from occurring within the clamps. For those cases where the outermost ribs are severed, the test results shall be based on the unit of width associated with the number of intact ribs." Hence, calculation of the secant modulus at certain strain domain shall be the maximum tensile force divided by the total intact with per meter. The strength and stiffness of the geogrid is load, time, and temperature dependent. The literature (Yeo 1985; Walters et al. 2002), stated that geogrid is affected by strain rate.

At CSR $10 \% / \mathrm{min}$, the derived secant modulus for stain domain of $2 \%$ are $390,536,868$, 1128 and $1396 \mathrm{KN} / \mathrm{m}$ for types A, B, C, D and E, respectively. The CSR trend for tensile strength versus secant modulus is illustrated at Fig. 5 The higher CSR reveals slight increase of the induced secant modulus. The larger ultimate strength, the higher anticipated secant modulus.

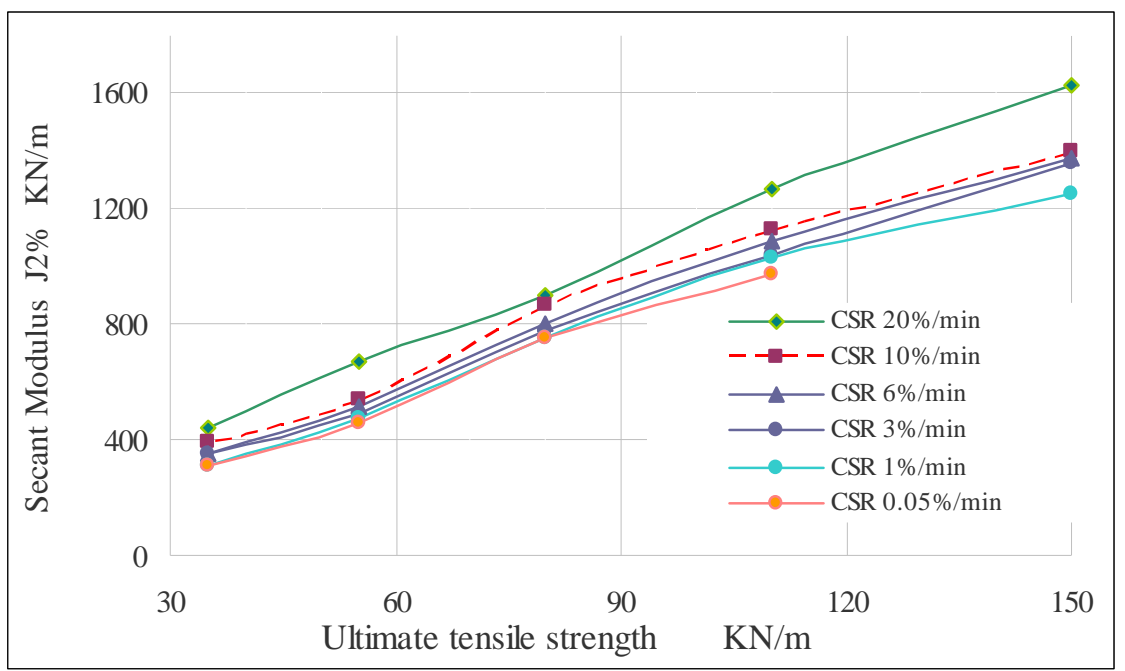

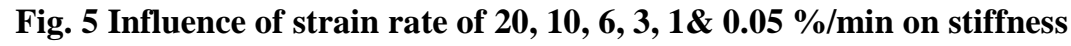




\section{ASSESSMENT FOR VARIATION OF STIFFNESS WITH TIME (CREEP} EFFECT).

Since the material is a polyester (PET) geogrid, the time-dependent stiffness reductions will be minimal of approximately $25-15 \%$ or less as concluded by (Allen and Bathurst 2001). Also, temperature sensitivity of PET is not as great as that for HDPE or PP geo-synthetics. For typical geo-synthetics in wall applications, the ratio of the modulus value at typical working conditions (i.e., strains on the order of $2 \%$ and loading times of approximately 1,000 hours) relative to the modulus obtained from typical CRS wide-width test (at strain $10 \% / \mathrm{min}$. ASTM D 4595) can be estimated for various geo-synthetics polymer types. Allen and Bathurst (2001) introduce a ratio stiffness modulus at 1000 hours $\mathbf{J}_{\text {1000hrs }} / \mathbf{J}_{\text {D4549 }}$ for polyester $(\mathrm{PET})=0.75$ to 0.85 .

To convert the measured reinforcement strain to the most accurate estimate of the actual reinforcement load, each measured strain was multiplied by the secant stiffness value that corresponds to the elapsed time. The time used to calculate the stiffness values was taken with respect to when the layer was installed in the field (Allen and Bathurst 2014). Consequently, series of CRS tests were conducted for rates of $20 \% / \mathrm{min}, 10 \% / \mathrm{min}, 6 \%$ $/ \mathrm{min}, 3 \% / \mathrm{min}, 1 \% / \mathrm{min}$ and $0.05 \% / \mathrm{min}$. Long term Stiffness for strain equaled $2 \%$ at 1000 hour (creep data from Walters et al. (2002)) was extrapolated as 0.75 multiplied by secant modulus at strain $2 \%$ measured from CSR of $10 \% / \mathrm{min}$. Ratios between stiffness (J2\%) to stiffness $(\mathrm{J} 1 \%)$ at the same time are evaluated as presented at Table $\mathbf{3}$ for sample of geogrid nominated type "D". Using this average ratio, stiffness at strain $1 \%$ after 1000 hour can be
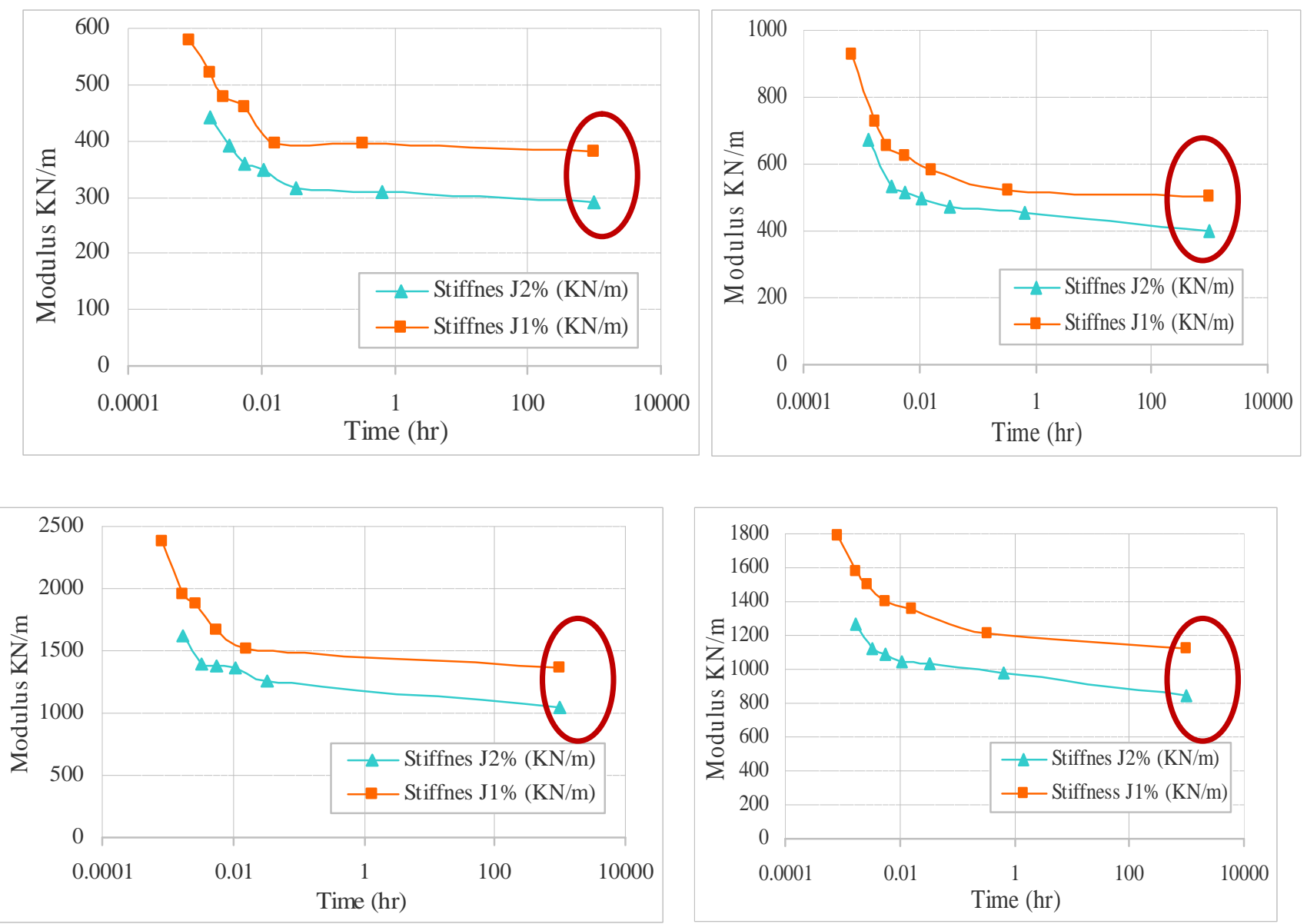


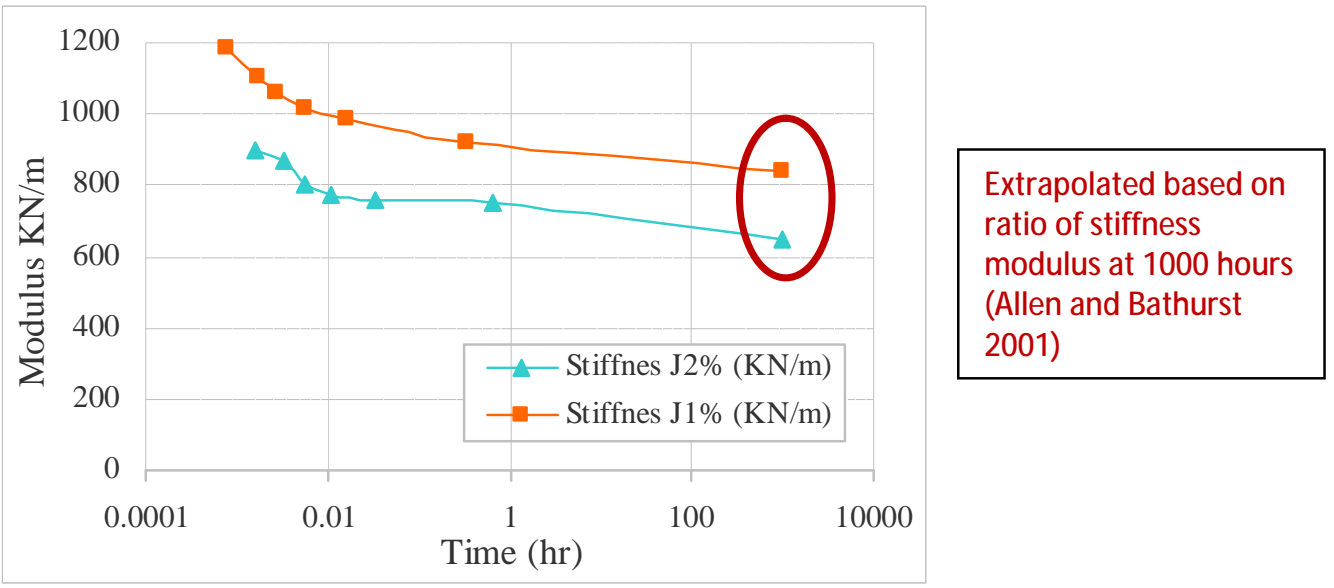

Fig. 6 Assessment for variation of stiffness @ 1\% \& 2\% strain with time

estimated. The stiffness value decreases with increasing logarithm of time but is reasonably constant after $1000 \mathrm{~h}$, as reported by (Miyata and Bathurst 2007). Fig. 6 shows assessment of variation for stiffness at $\mathrm{J} 1 \%$ and $\mathrm{J} 2 \%$ strains for the elapsed time which defined till end of construction for each layer.

Table 3: Secant modulus @ 1\% \& 2\% strain for sample type "D” with elapsed time

\begin{tabular}{|c|c|c|c|c|c|c|c|}
\hline $\begin{array}{c}\text { CSR } \\
\% / \mathrm{min} .\end{array}$ & $\begin{array}{l}\text { Time to } \\
1 \%(\mathrm{hr})\end{array}$ & $\begin{array}{l}\text { Time to } \\
2 \%(h r)\end{array}$ & $\begin{array}{c}\text { Force } \\
\mathbf{1 \%} \\
(\mathbf{k N})\end{array}$ & $\begin{array}{l}\text { Secant } \\
1 \%(\mathbf{k N})\end{array}$ & $\begin{array}{c}\text { Force } \\
\mathbf{2 \%} \\
(\mathbf{k N})\end{array}$ & $\begin{array}{c}\text { Secant } \\
\mathbf{2 \%} \\
(\mathbf{k N})\end{array}$ & $\begin{array}{c}\text { Ratio } \\
\mathbf{J}_{2} \% / \mathbf{J}_{\mathbf{1}} \%\end{array}$ \\
\hline 20 & 0.0008 & 0.00167 & 17.92 & 1792 & 25.34 & 1267 & 1.41 \\
\hline 10 & 0.0017 & 0.00333 & 15.83 & 1583 & 22.55 & 1128 & 1.40 \\
\hline 6 & 0.0028 & 0.00556 & 15.00 & 1500 & 21.84 & 1092 & 1.37 \\
\hline 3 & 0.0056 & 0.01111 & 13.96 & 1396 & 20.86 & 1043 & 1.34 \\
\hline 1 & 0.0167 & 0.03333 & 13.54 & 1354 & 20.66 & 1033 & 1.31 \\
\hline 0.05 & $\mathbf{0 . 3 3 3 3}$ & 0.66667 & 12.08 & 1208 & 19.51 & 976 & 1.24 \\
\hline Creep & 1000 & 1000 & & 1127 & & 846 & 1.33 \\
\hline
\end{tabular}

\section{CALIBRATION FACTOR BETWEEN LOCAL TO GLOBAL STRAIN}

Strain readings from high-elongation strain gauges glued to the reinforcement material must be calibrated against the "true" global strain in the reinforcement as reported by Allen et al. (2002). The Calibration Factor CF for a particular combination of gauge, bonding technique, reinforcement polymer type, and location of gauge is typically established from constant-rate-of-strain in-isolation wide-width strip tensile testing (ASTM D 4595) as reported by Allen et al. (2002). Hence, strain gauge readings in the field must be corrected to true global strains using in- isolation tensile tests of instrumented reinforcement geogrids. In order to better match the realistic (slower) loading conditions of a geogrid layer placed within a wall during construction, the data from the $0.05 \% / \mathrm{min}$ CRS test was used for Calibration. Geogrid types were tested under CSR of $10 \% / \mathrm{min}$ as nominal value introduced by ASTM 4595 and at low strain range of $0.05 \% / \mathrm{min}$ in the domain of 0 to $3 \%$ strain to match the maximum working conditions (no need to reach the strain at break). No calibration tests were performed for type " $E$ " (of the highest strength of the five testes specimens) as the instrumentation program does not install any strain gauges to that type. For CSR testing of $0.05 \% / \mathrm{min}$, an interval of local strain readings equals to $2.0 \mathrm{~min}$ utilized to reveal approximately 30 readings through the strain domain of $3 \%$. While, for CSR $10 \% / \mathrm{min}$, and due to the sensitivity of relatively rapid test loading and possible associated 
missing/ errors for recording the initial significant readings of local strain by data logger; two sets were examined for local strain readings of intervals $2 \mathrm{sec}$ and $1 \mathrm{sec}$, to result in about 30 and 60 readings, respectively to reach the failure. However, only limited number of readings (approximate to 10 or 20) at domain of strain 3\%; which is not liable relative to CSR of $0.05 \% / \mathrm{min}$. Fig. 7 plotted the local strain versus global strain for various tested geogrid types. Calibration Factor values slightly increased as strain rate decreased. A nominal average best fit values for $\mathrm{CF}$ of 2.08, 2.05, 2.02 and1.99 were derived appropriate for such foil strain gauges glued to PET geogrid type A, B, C and D respectively. In other words, the strain gauge values must be doubled to represent "true" global strains. This CF estimation for strain levels of $2 \%$ or less is in agreement with comparable PET geogrid CF of 2.2, which was introduced by Allen et al. (2002). It can be argued that the actual loading history of a geogrid layer during construction falls between the two idealized loading conditions performed in the laboratory. Fig. 8 shows the test setup adopted for derivation of CF.
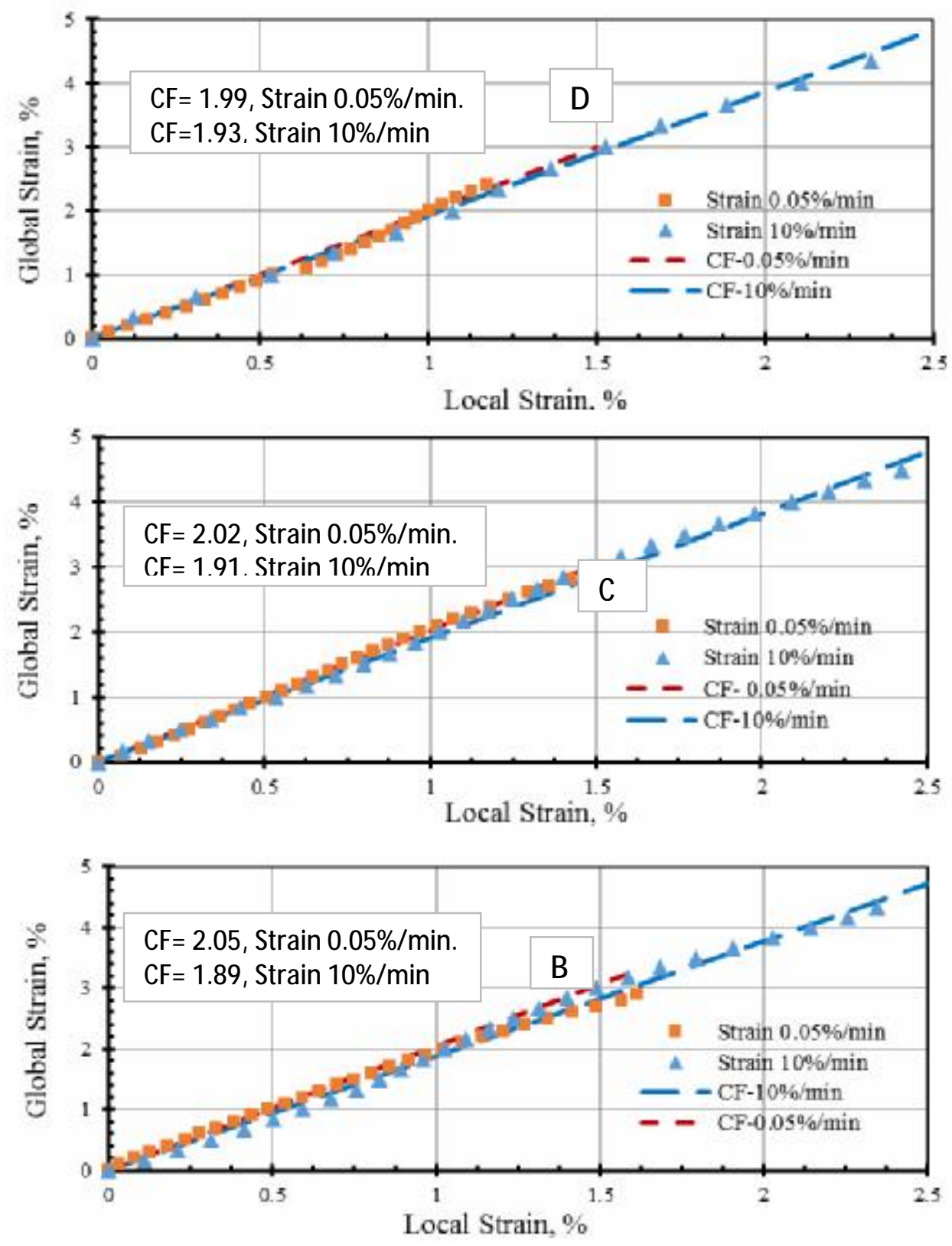


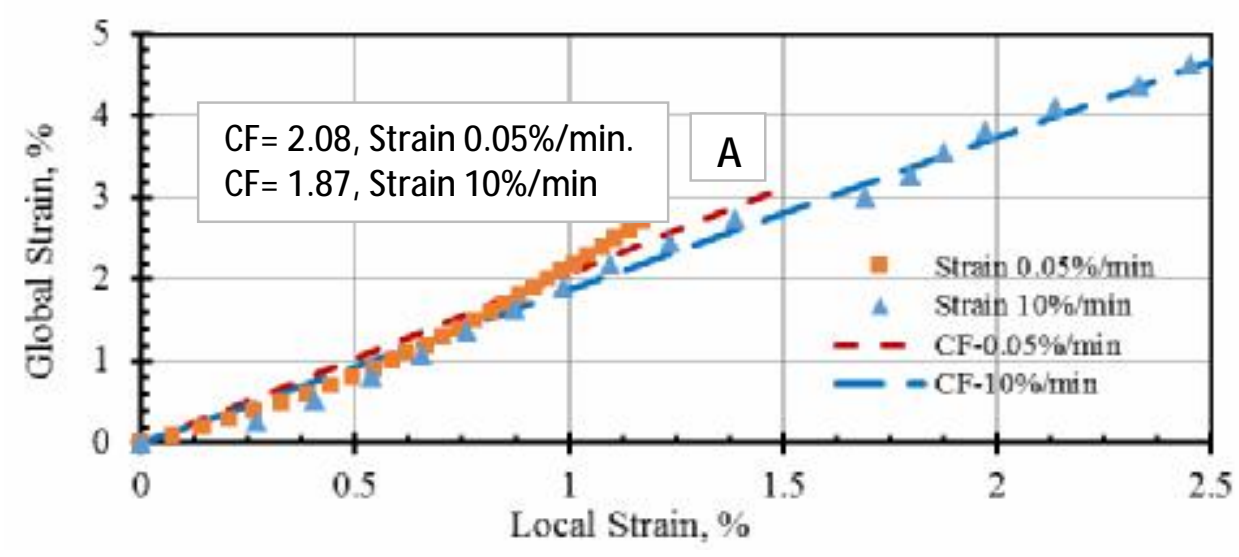

Fig. 7 CSR test; In-isolation local strain gauge response versus global strain

It was identified that, to adapt the measured reinforcement strain to the most accurate estimate of the actual reinforcement load, each measured strain was multiplied by the secant stiffness value that corresponds to the elapsed time. The stiffness value used was taken at a strain equal to the measured strain. The time used to calculate the stiffness values was taken with respect to when the layer was installed in the field (Allen and Bathurst 2014).
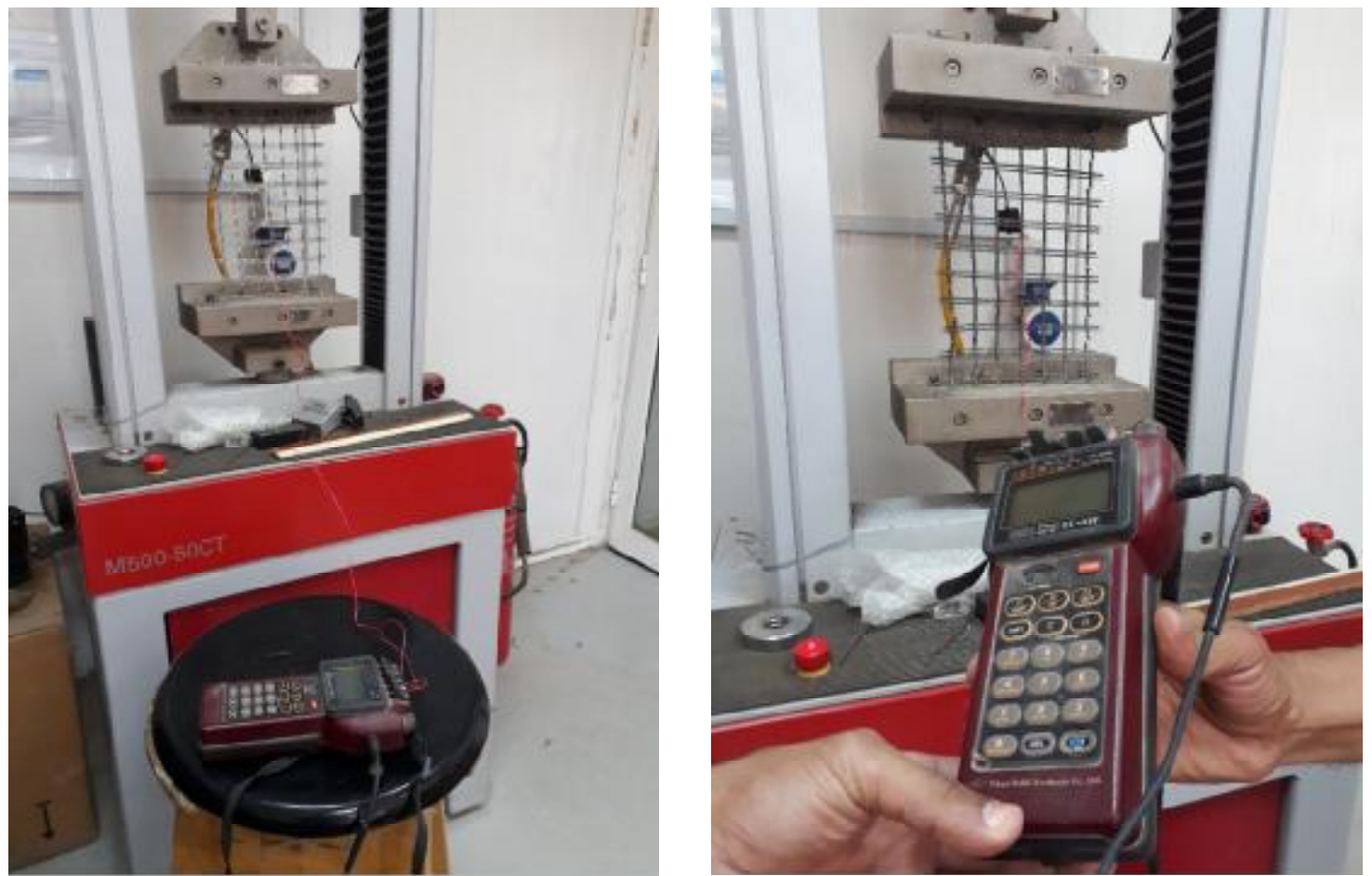

Fig. 8 CSR test setup adopted for derivation of CF

\section{GEOGRID SIMULATION IN NUMERICAL MODEL}

The linear approximation of secant modulus (after creep consideration) is considerable accepted in the strain domain up to $2 \%$ which covers a wide scatter of Geosynthetics reinforced structures conditions under service loadings as concluded by Hatami and Bathurst (2005). 


\section{CONCLUSIONS}

This paper is a portion of a wide-ranging research to better identify the behavior and material characterization of Geosynthetics reinforced structures using polyester (PET) geogrid. Constant Strain Rate CSR tests were carried out for the used PET geogrids at MD in accordance with ASTM D6637 using "the multi-rib geogrid test" to justify tensile ultimate strength, and Strain at break; results are in good agreement with manufactures technical data sheet. Values for Secant modulus J at strain level $1 \%$ \& $2 \%$ were derived from the tensile force- strain relationship results, which are necessary numerical FE molding. The influence for strain loading rate was assessed on strength and stiffness of the different polyester specimens. We are focused on simulations that can be used to predict operational (working stress) under static conditions rather than incipient collapse. The main findings might be summarized as follows:

- The higher CSR reveals increase of the measured secant modulus. The larger the ultimate strength, the higher anticipated secant modulus.

- Calibration Factor CF between global to local strains ranged from 2.08 to 1.99 was introduced appropriately for the tested polyester geogrid specimens at stain domain of $2 \%$. This CF estimation for strain levels of $2 \%$ or less- based on the CSR test- is in worthy agreement with comparable PET geogrid CF of 2.2, which was introduced by Allen et al. (2002).

- To assess the long-term parameter and creep effect, a series of CRS tests were conducted for different strain rates of $20 \%, 10 \% / \mathrm{min}, 6 \% / \mathrm{min}, 3 \% / \mathrm{min}, 1 \% / \mathrm{min}$, and $0.05 \% / \mathrm{min}$. Outcome response is in good agreement with consensus that, for polyester (PET) geogrid, time-dependent stiffness reductions will be minimal (approximately $25-15 \%$ or less).

- The linear approximation of secant modulus (after creep consideration) is considerable accepted in the strain domain up to $2 \%$ which covers a wide scatter of Geosynthetics reinforced structures conditions under service loadings.

\section{REFERENCES}

1. AASHTO (2002). Standard Specifications for Highway Bridges. American Association of State Highway and Transportation Officials, 17th Ed., Washington, DC, USA.

2. Allen, T. M., and Bathurst, R. J. (2002a). "Observed long-term performance of geo-synthetic walls, and implications for design." Geo-synthetic Int., 9(5-6), 567-606.

3. Bathurst, R.J., Allen, T.M., and Walters, D.L., 2002, "short-term strain and deformation behaviour of geo-synthetic walls at working stress conditions", geo-synthetics international, vol. 9, nos. 5-6, pp. 451-482.

4. ASTM D 6637. "Standard Test Method for Determining Tensile Properties of Geogrids by the Single or Multi-rib Tensile Method." American Society for Testing and Materials, Pennsylvania, USA.

5. Bathurst, R. J., Allen, T. M., and Walters, D. L. (2002). "Short-term Strain and Deformation Behaviour of Geo-synthetic Walls at Working Stress Conditions," Geo-synthetic. Int., 9(5- 6), pp. 451-482.

6. Hatami, K. and Bathurst, R. J. (2005). "Development and verification of a numerical model for the analysis of geo-synthetic-reinforced soil segmental walls under working stress conditions." Journal of Geotechnical and Geo-environmental Engineering, ASCE, 132(6), 673684.

7. Hatami, K. and Bathurst, R. J. (2006). "Numerical model for reinforced soil segmental walls under surcharge loading." Canadian Geotechnical Journal, 67(4), 10661085.

8. Huang, B., Bathurst, R.J., and Hatami K. (2009). "Numerical Study of Reinforced Soil Segmental Walls Using Three Different Constitutive Soil Models," Journal of Geotechnical and Geoenvironmental Engineering, Vol. 135, No. 10, October 1. 